ASEE's 123rd Annual • Conference \& Exposition • New Orleans, LA • June 26-29, 2016

\title{
Self-Efficacy in Senior Design: Effects of Time and Team
}

Dr. Elif Miskioglu, Bucknell University

Elif Miskioglu is currently a Visiting Assistant Professor of Chemical Engineering at Bucknell University. She graduated from Ohio State University in 2015 with a PhD in Chemical Engineering, and is interested in student learning in engineering. 


\title{
Self-Efficacy in Senior Design: Effects of Time and Team
}

\begin{abstract}
Much of traditional curriculum is designed around individual assessment, but throughout their career most engineers are more likely to be assessed as part of a team. Having studied selfefficacy and learning styles in sophomore students for several semesters and noticing trends that may be explained by their early stage in career (e.g., lack of confidence in conceptual problems), we began to consider the status of our graduating senior students. Are they entering the workforce with high self-efficacy and a command of chemical engineering theory and design principles?
\end{abstract}

Using a modified version of the Carberry et al. instrument for design self-efficacy, we tracked student self-efficacy throughout their senior design experience. Three self-efficacy surveys were administered: one early in the term while students were working on an individual project, one in the mid-semester while students were balancing an individual project with a team project, and a final one at the end-of-semester when only a final team project remained. This three project structure, two individual and one team, allowed us to examine both the design experiences and team effects on student self-efficacy.

A wide number of self-efficacy gains suggest that students' self-efficacy is positively affected by our senior design class. Patterns of self-efficacy gains indicate that there may be a timedependent variable that affects the development of students' self-efficacy. A higher number of observed self-efficacy gains between surveys 1 and 2 suggests that the steeper learning curve during the first half of the course may allow for high gains in self-efficacy. Students are thrust in a course that expects expert level results, but have very little design experience prior. This simple fact may have a greater influence on self-efficacy than team dynamics as fewer gains were observed between survey 2 and 3. Between surveys 1 and 2, and surveys 2 and 3, students gained confidence in conducting design, and evaluating and testing a design. The continual increase in self-efficacy toward these items throughout the term promotes the value of both individual and team projects in assisting with the development of self-efficacy. Between surveys 2 and 3 (project focus was at this point entirely team-based), students' self-efficacy with respect to selecting the best possible design showed statistically significant gains. Student confidence in making important decisions such as design selection may increase when discussed among and validated by a team.

A better understanding of students' self-efficacy maturation during the senior design experience will allow for development of an improved senior design course, and closer inspection of prerequisite courses may allow for development of a more integrated and effective curriculum.

\section{Overview of Work and Methods}

At our institution, senior design is a one-semester course consisting of three projects: two individual and one team. This enables a unique opportunity to track student self-efficacy, described as belief in their own individual capability, ${ }^{1-5}$ and the potential influence of team dynamics on that self-efficacy. That is, do students with positive team experiences see greater gains in self-efficacy than students with poor team dynamics and cohesion? 
Using a modified version of Carberry et al.'s senior design self-efficacy tool, ${ }^{6}$ we examined potential correlations between self-efficacy, team dynamics/cohesion, and team performance. Students were given three self-efficacy surveys, one early in the term, one mid-term, and one late in the term, corresponding to times where they were working on an individual project only, both on an individual project and group project, and just on a group project.

Because we have had low participation in past studies, we were hesitant to use the full Carberry instrument that contains 36 items (nine items in the context of four self-concepts: self-efficacy, motivation, outcome expectancy, and anxiety). We also wanted to include our own questions regarding future career plans, ability to recall previous coursework, and attitude toward design and associated skills. Because there is no requirement or incentive to complete the survey, it is in our interest to make it as quick to complete and simple as possible. For that reason, we reduced the Carberry instrument to no more than two self-concepts (self-efficacy for all three surveys, and anxiety in surveys 2 and 3 ).

The course uses Comprehensive Assessment of Team Member Effectiveness (CATME) to capture and assess team dynamics. ${ }^{7-9}$ CATME provides summary and analysis of teams and individuals based on a set of algorithms, and in certain cases flags individuals as "exceptional conditions" such as those demonstrating underconfidence, overconfidence, high performance, low performance, and potential conflict with a team member.

A matched pairs ANOVA, followed by Tukey test, and Kruskal-Wallis, followed by a SteelDwass test, were used with a significance level of 0.05 for all numeric variables. For categorical data, Pearson's Chi-squared test was used, and in cases where the contingency table contained values that were less than five, the Fisher's Exact test.

\section{Results and Discussion: Student Self-Efficacy}

For this study cycle, our sample size was 78 students. On many survey items, we observe that student self-efficacy increased during the term. Table 1 summarizes the gains in student efficacy between surveys 1 and $2(*)$, and 2 and $3\left(^{\wedge}\right)$. Items 1 through 9 represent self-efficacy items included on all three surveys, items 10 through 16 are general perception items included on all three surveys, and items 17 through 25 are anxiety items included on just surveys 2 and 3 . For all self-efficacy items, the change in response between surveys was in the direction of increased self-efficacy. All statistical significance is in the direction of increased confidence/agreement/decreased anxiety, except for in the case of item 10, the only perception item to show a significant difference (in the direction of decreasing agreement). The mean difference of the matched pairs student responses is also provided. Because changes in individual student responses are of interest (matched pairs), this number is more meaningful than the mean responses on survey items. It is important to highlight that of the 78 students enrolled, 53 students completed surveys 1 and 2, and 23 students completed surveys 2 and 3 . Additionally, it is important to keep in mind when considering the numerical averages of student responses that the act of taking such an average assumes interval variables. 
Table 1. Items on self-efficacy and perceptions instrument administered in senior design. An asterisk (*) indicates items where a statistically significant difference in matched pairs response was observed between Survey 1 and $2(\mathrm{~S} 1-\mathrm{S} 2)$, and a caret $\left({ }^{\wedge}\right)$ represents items for which a statistically significant difference was observed between Survey 2 and 3 (S2-S3). Items 17 to 25 were administered only on Surveys 2 and 3. A positive mean difference in a response refers to an average increase in matched pairs responses to the item on a 5-point Likert scale, and a negative mean difference refers to an average decrease.

\begin{tabular}{|c|c|c|c|}
\hline \multirow[t]{2}{*}{ Question \# } & \multirow[t]{2}{*}{ Question Text } & \multicolumn{2}{|c|}{$\begin{array}{l}\text { Mean Difference } \\
\text { in Response }\end{array}$} \\
\hline & & $\begin{array}{c}\mathrm{S} 1-\mathrm{S} 2 \\
(\mathrm{~N}=53)\end{array}$ & $\begin{array}{c}\mathrm{S} 2-\mathrm{S} 3 \\
(\mathrm{~N}=23)\end{array}$ \\
\hline \multicolumn{4}{|c|}{ Self-Efficacy (certainty in ability to do...) Items on All Surveys } \\
\hline $1=$ cannot & $2=$ might be able $3=$ moderate $\quad 4=$ considerably certain & \multicolumn{2}{|c|}{$5=$ highly certain } \\
\hline 1 & $\begin{array}{l}*, \wedge \text { Rate your degree of confidence in performing the following } \\
\text { task: conduct engineering design. }\end{array}$ & 0.25 & 0.30 \\
\hline 2 & $\begin{array}{l}\text { * Rate your degree of confidence in performing the following } \\
\text { task: identify a design need. }\end{array}$ & 0.23 & 0.26 \\
\hline 3 & $\begin{array}{l}\text { Rate your degree of confidence in performing the following } \\
\text { task: research a design need. }\end{array}$ & 0.13 & 0 \\
\hline 4 & $\begin{array}{l}\text { * Rate your degree of confidence in performing the following } \\
\text { task: develop design solutions. }\end{array}$ & 0.35 & 0.17 \\
\hline 5 & $\begin{array}{l}\wedge \text { Rate your degree of confidence in performing the following } \\
\text { task: select the best possible design. }\end{array}$ & 0.21 & 0.61 \\
\hline 6 & $\begin{array}{l}\text { Rate your degree of confidence in performing the following } \\
\text { task: develop a simulation for a design. }\end{array}$ & 0.19 & 0.22 \\
\hline 7 & $\begin{array}{l}*, \wedge \text { Rate your degree of confidence in performing the following } \\
\text { task: evaluate and test a design. }\end{array}$ & 0.27 & 0.43 \\
\hline 8 & $\begin{array}{l}\text { * Rate your degree of confidence in performing the following } \\
\text { task: communicate a design. }\end{array}$ & 0.29 & 0.04 \\
\hline 9 & $\begin{array}{l}* \text { Rate your degree of confidence in performing the following } \\
\text { task: redesign. }\end{array}$ & 0.29 & 0.22 \\
\hline \multicolumn{4}{|c|}{ General Perceptions (agreement with the following...) } \\
\hline \multicolumn{4}{|c|}{$1=$ strongly disagree $\quad 2=$ disagree $\quad 3=$ neutral $\quad 4=$ strongly agree 5} \\
\hline 10 & $\wedge$ Design skills are important for chemical engineers. & 0 & -0.22 \\
\hline 11 & $\begin{array}{l}\text { It is important to know the theory (governing equations and } \\
\text { principles) behind engineering design. }\end{array}$ & -0.15 & 0.09 \\
\hline 12 & I will use engineering design principles in my career. & -0.11 & 0.09 \\
\hline 13 & I intend to pursue a career in chemical engineering. & 0.07 & -0.09 \\
\hline 14 & $\begin{array}{l}\text { I have been able to recall the theory I learned in previous } \\
\text { courses and apply it to the design. }\end{array}$ & 0.04 & -0.09 \\
\hline
\end{tabular}




\begin{tabular}{|c|c|c|c|}
\hline 15 & $\begin{array}{l}\text { I have had difficulty recalling the appropriate theory from } \\
\text { previous courses that is needed to proceed with the design. }\end{array}$ & -0.21 & 0 \\
\hline 16 & $\begin{array}{l}\text { I intend to pursue a career that deviates from chemical } \\
\text { engineering. }\end{array}$ & -0.04 & -0.09 \\
\hline \multicolumn{4}{|c|}{ Anxiety Items (anxiety in performing the following...) on Surveys 2 and 3} \\
\hline \multicolumn{4}{|c|}{$1=$ none $\quad 2=$ little $\quad 3=$ moderate $\quad 4=$ considerable $\quad 5=$} \\
\hline 17 & $\begin{array}{l}\wedge \text { Rate your degree of anxiety in performing the following tasks: } \\
\text { conduct engineering design }\end{array}$ & N/A & -0.30 \\
\hline 18 & $\begin{array}{l}\wedge \text { Rate your degree of anxiety in performing the following tasks: } \\
\text { identify a design need. }\end{array}$ & N/A & -0.35 \\
\hline 19 & $\begin{array}{l}\text { Rate your degree of anxiety in performing the following tasks: } \\
\text { research a design need. }\end{array}$ & N/A & -0.22 \\
\hline 20 & $\begin{array}{l}\text { Rate your degree of anxiety in performing the following tasks: } \\
\text { develop design solutions. }\end{array}$ & N/A & -0.30 \\
\hline 21 & $\begin{array}{l}\wedge \text { Rate your degree of anxiety in performing the following tasks: } \\
\text { select the best possible design. }\end{array}$ & N/A & -0.57 \\
\hline 22 & $\begin{array}{l}\text { Rate your degree of anxiety in performing the following tasks: } \\
\text { develop a simulation for a design. }\end{array}$ & N/A & -0.22 \\
\hline 23 & $\begin{array}{l}\wedge \text { Rate your degree of anxiety in performing the following tasks: } \\
\text { evaluate and test a design. }\end{array}$ & N/A & -0.44 \\
\hline 24 & $\begin{array}{l}\text { Rate your degree of anxiety in performing the following tasks: } \\
\text { communicate a design. }\end{array}$ & N/A & -0.09 \\
\hline 25 & $\begin{array}{l}\text { Rate your degree of anxiety in performing the following tasks: } \\
\text { redesign. }\end{array}$ & N/A & -0.13 \\
\hline
\end{tabular}

From survey 1 to survey 2, we observe a general increase in self-efficacy with respect to: conducting engineering design, identifying a design need, develop design solutions, evaluate and test a design, communicate a design, and redesign. Between surveys 2 and 3, students reported an increased self-efficacy with respect to: conducting engineering design, select the best possible design, and evaluate and test a design. Gains in self-efficacy related to conducting engineering design, and evaluate and test a design are seen in both intervals. This suggests that senior design is well tailored toward providing students an opportunity to make incremental gains with respect to self-efficacy in these areas throughout the term. A number of items showed statistical significance between surveys 1 and 2, but not between 2 and 3, suggesting that the highest gains in self-efficacy for these items (identify a design need, develop a solution, communicate a design, and redesign) may be early in the class when students are experiencing a steep learning curve as they are introduced to design. Self-efficacy with respect to selecting the best possible design, however, only showed significant gains between surveys 2 and 3, suggesting that selfefficacy in selecting the design may be positively impacted by working in a team, as well as accumulating experience. Structured discussions that improve design selection, and possibly affirm students' independent ideas, may lead to a group influenced gain in self-efficacy.

For items asked only on surveys 2 and 3, students reported overall gains in self-efficacy (as a decrease in anxiety) toward: conduct engineering design, identify a design need, select the best 
possible design, evaluate and test a design. Of these four items, all but identifying a design need correspond directly to gains in self-efficacy (reported as increased confidence) between surveys 2 and 3. While it seems that students would experience low anxiety and confidence simultaneously, it could be that the use of the verb "confidence" may have been off-putting to students early in their design careers. Thus, while they may say that they are not anxious about identifying a design need, they may also be hesitant to claim they are confident in this.

These varied results in self-efficacy gains between administered surveys suggests that either the nature of learning design, or the specific approach in this course, supports time-dependent gains in self-efficacy. When considering the design process, some items (such as those that showed gains between surveys 1 and 2 may be a prerequisite (of sorts) for gains in other areas, accounting for why statistically significant gains were only observed during one portion of the semester.

At first glance it is disheartening that item 10, "design skills are important for engineers" showed a statistically significant decrease in agreement between surveys 2 and 3. Examining student comments shows that by the third survey, students were in many cases frustrated with their client, communication, or lack of direction. This response to their first truly open-ended problem solving experience suggests that students might be struggling to bridge their academic content knowledge with messy, often unclear and undefined, real-world applications. Arguably, this is part of the design experience, however, several U.S. institutions are proponents of "designbased" coursework throughout the curriculum to provide students more opportunities to experience more realistic problems.

With regards to team dynamics, most teams reported positive interactions. In peer evaluation 1 , only three of the 21 senior design teams made comments indicative of conflict (communication problems, uneven workload, etc.). In peer evaluation 2, however, that increased to one third (7 of 21 ) of the teams having one or more comment suggesting a team dynamic or cohesion issue. This increase in reports of negative team-cohesion may be reflective of end-of-term stress and frustration of working under pressure potentially captured by the timing of peer evaluation 2 . Only one team, Team B, reported team dynamic issues in both peer evaluation 1 and 2, suggesting that other teams were able to resolve some of their early conflicts. This also further supports the theory that end-of-term stress may be a factor in more teams reporting negative cohesion, as these teams did not report cohesion issues early in the term. It is possible that when work was relatively easier, their problems were either masked or non-existent, but then the urgency of final deadlines brought dynamics issues to the forefront. This observation may also inform a potential course improvement in providing more closely guided team dynamics support to students as the term comes to an end. Being able to work under pressure, and to do so with a team, is an essential engineering professional skill for our students. But, since we often focus on team dynamics conversations and coaching at the beginning of any team experience, we may be missing an opportunity to provide just-in-time guidance and facilitate even greater growth of team skills by actively re-engaging in coaching near the end of the experience.

\section{Conclusions and Future Work}

We observe that senior design has a positive effect on self-efficacy, as gains were evident in the majority of items measured. There is, however, a time-dependency (which may suggest an 
experience-dependency) of these gains. Some items saw gains only between surveys 1 and 2, and others only between 2 and 3. This suggests that factors of the natural course progression, and perhaps the teamwork that is begun between surveys 2 and 3, play a role in fostering different self-efficacy gains. A greater number of items showed gains between surveys 1 and 2, however, suggesting that the steep learning curve associated with the early part of the semester may have a stronger effect on self-efficacy development than team dynamics. This requires further investigation.

Confidence in conducting design and evaluating and testing a design showed gains between both surveys 1 and 2, and 2 and 3. It is not surprising that students would feel increased confidence as they gain more experience, and the building of this confidence throughout the term is an encouraging indicator that each project is value-added. Student self-efficacy with respect to selecting the best possible design only showed statistical significance (in the direction of higher self-efficacy) between surveys 2 and 3, which corresponds with the transition from individual projects to group work. This may reflect that student confidence in making decisions such as design selection increases when discussed and validated by others (team members).

In the early part of their teamwork, only 3 of 21 teams showed evidence of team cohesion/dynamics issues. This number increased to 7 of 21 teams by the end of term, which is not surprising given that increased stress can often lead to increase in frustration, impatience, and other attributes that may negatively affect teamwork. What is interesting, however, is that of these seven teams, only one reported negative team cohesion in the early part of the term. This suggests that some teams experience conflict early, but are able to resolve it, while others experience conflict when under higher stress near deadlines, and in the case of a semester long course may not get a chance to resolve it. In future work, we will continue to observe changes in team dynamics, and develop new coaching strategies for the last portion of the group project to provide student teams with the support they need, and the opportunity to learn how to manage conflict under stress.

Design self-efficacy and positive teamwork skills are essential components to a successful engineering career. We observe that our students are gaining self-efficacy throughout their senior design experience, however, we may have room for improvement in teaching them about teamwork, and specifically conflict management. This can be accomplished through more focused coaching, which we also believe will have positive impacts on self-efficacy.

\section{Acknowledgements}

Thank you to Dr. David Tomasko for allowing access to his course, and Drs. James Rathman and David Wood for their support and contributions to this work.

\section{References}

1 Bandura, A. Self-efficacy : the exercise of control. (W.H. Freeman, 1997).

2 Bandura, A. Social foundations of thought and action : a social cognitive theory. (Prentice-Hall, 1986). 
3 Bandura, A. Self-efficacy: toward a unifying theory of behavioral change. Psychological review 84, 191215 (1977).

4 Bandura, A. in Self-efficacy beliefs of adolescents (eds Frank Pajares \& Timothy C Urdan) Ch. 14, (IAP, 2006).

5 Bandura, A. Self-efficacy conception of anxiety. Anxiety Research 1, 77-98, doi:10.1080/10615808808248222 (1988).

6 Carberry, A. R., Lee, H.-S. \& Ohland, M. W. Measuring Engineering Design Self-Efficacy. Journal of Engineering Education 99, 71-79, doi:10.1002/j.2168-9830.2010.tb01043.x (2010).

7 Ohland, M. et al. CATME and Team-Maker Tools for Teamwork. (2009).

8 Ohland, M., Loughry, M. \& Carter, R. Comprehensive Assessment of Team Member Effectiveness. CATME), A New Peer Evaluation Instrument (2006).

9 Ohland, M. W. et al. in Proceedings of the 2006 ASEE Annual Conference. 